\title{
Why grit requires perseverance and passion to positively predict performance
}

\author{
Jon M. Jachimowicz ${ }^{\mathrm{a}, 1}$, Andreas Wihler ${ }^{\mathrm{b}}$, Erica R. Bailey ${ }^{\mathrm{a}}$, and Adam D. Galinsky ${ }^{\mathrm{a}}$ \\ ${ }^{a}$ Management Division, Columbia Business School, New York, NY 10025; and ${ }^{\mathrm{b}}$ Management Department, Frankfurt School of Finance \& Management, \\ 60322 Frankfurt am Main, Germany
}

Edited by Susan T. Fiske, Princeton University, Princeton, NJ, and approved August 17, 2018 (received for review March 1, 2018)

\begin{abstract}
Prior studies linking grit-defined as perseverance and passion for long-term goals-to performance are beset by contradictory evidence. As a result, commentators have increasingly declared that grit has limited effects. We propose that this inconsistent evidence has occurred because prior research has emphasized perseverance and ignored, both theoretically and empirically, the critical role of passion, which we define as a strong feeling toward a personally important value/preference that motivates intentions and behaviors to express that value/preference. We suggest that combining the grit scalewhich only captures perseverance-with a measure that assesses whether individuals attain desired levels of passion will predict performance. We first metaanalyzed 127 studies $(n=45,485)$ that used the grit scale and assessed performance, and found that effect sizes are larger in studies where participants were more passionate for the performance domain. Second, in a survey of employees matched to supervisor-rated job performance $(n=422)$, we found that the combination of perseverance, measured through the grit scale, and passion attainment, measured through a new scale, predicted higher performance. A final study measured perseverance and passion attainment in a sample of students $(n=248)$ and linked these to their grade-point average (GPA), finding that the combination of perseverance and passion attainment predicted higher GPAs in part through increased immersion. The present results help resolve the mixed evidence of grit's relationship with performance by highlighting the important role that passion plays in predicting performance. By adequately measuring both perseverance and passion, the present research uncovers grit's true predictive power.
\end{abstract}

grit | perseverance | passion | performance | motivation

T he concept of grit has captured the public imagination. Angela Duckworth's 2013 TED talk introduced grit to a broad audience and described it as an important predictor of future success; the talk clearly resonated with audiences, as it has over 14 million views to date (1). Her subsequent 2016 book, Grit: The Power of Passion and Perseverance, became an international best-seller (2). Grit has also crept into educational policy throughout the United States, influencing the design of school curriculums to boost their future success by making students "grittier" (3). These developments are seemingly occurring for good reason: prior studies have found that grit relates to several intermediaries of success, including increased deliberate practice (4), sustained retention in difficult jobs $(5,6)$, and task persistence (7).

Given the widespread attention and initial evidence, one would expect to find copious studies showing that grit predicts performance. Surprisingly, evidence linking grit and performance is beset by contradictory empirical results. A recent metaanalysis, as well as high-powered empirical studies, have found a weak or nonsignificant relationship between grit and various indicators of success (8-10). Because the evidence regarding the relationship between grit and performance has been inconclusive, several commentators have stated that grit is "overrated," "limited," "hyped," and "under attack" (11-14).

We propose that the inconsistency between grit's initial promise and its subsequent lack of empirical support has occurred because grit's measurement has not matched its definition. Duckworth et al. (5) define grit as "perseverance and passion for long-term goals." Although this definition of grit contains two conceptual components—-perseverance and passion-we suggest that the grit literature, and consequently its measurement, has focused only on perseverance and has not adequately captured passion. The tight link between grit and perseverance has even made its way into online thesauruses: on https://www.thesaurus.com/, synonyms of perseverance include grit and synonyms of grit include perseverance, but neither includes passion.

The issue is not just conceptual but also methodological. We propose that the current measure of grit likely reflects perseverance alone. Indeed, studies that find effects of the grit scale on performance-related outcomes are highly connected to perseverance (e.g., increased deliberate practice, sustained retention, and task persistence). We suggest that passion is key to grit but missing in its theory and measurement, which as a result, has produced the empirical inconsistencies found in the grit literature.

Overall, academics and popular commentators alike frequently equate grit with perseverance alone and neglect the passion component. Prominent educational psychologist Mike Rose, critiquing grit, states, "[r]ather than calling their construct 'perseverance' or 'persistence,' they chose to call it 'grit'" (15). Similarly, consider that a metaanalysis of the grit literature refers to grit as "a personality trait" (8), and compares grit to

\section{Significance}

Grit has captured the public imagination and crept into educational policy throughout the United States. However, because prior studies linking grit and performance are beset by contradictory evidence, commentators increasingly state that grit is overhyped. We propose that the inconsistency between grit's initial promise and its subsequent lack of empirical support has occurred because grit's measurement has not matched its definition. Although grit is defined as the combination of perseverance and passion, its measurement has focused on perseverance and has not adequately captured passion. In a metaanalysis of 127 studies and two field studies, we show that passion is a key component of grit. The current theory and results suggest that perseverance without passion isn't grit, but merely a grind.

Author contributions: J.M.J. designed research; J.M.J. and E.R.B. performed research J.M.J., A.W., and E.R.B. analyzed data; and J.M.J., A.W., E.R.B., and A.D.G. wrote the paper.

The authors declare no conflict of interest.

This article is a PNAS Direct Submission.

Published under the PNAS license.

Data deposition: Data and scripts related to this paper are available at https://osf.io/ $\mathrm{kp} 7 \mathrm{cb} /$.

${ }^{1}$ To whom correspondence should be addressed. Email: jmj2183@columbia.edu.

This article contains supporting information online at www.pnas.org/lookup/suppl/doi:10 1073/pnas.1803561115/-/DCSupplemental.

Published online September 17, 2018. 
conscientiousness in their analyses. Angela Duckworth herself noted this shortcoming of the theory and measurement of grit, stating that she is thinking about revising her grit scale, "specifically the questions about passion" (16).

The neglect of passion in the measurement of grit is particularly problematic because prior research stresses that passion produces beneficial effects on performance through a key mechanism: immersion. Several studies converge on the idea that the combination of perseverance and passion may heighten individuals' immersion in a performance domain-that is, the intensity of focus experienced-which may in turn promote higher levels of performance (17-20). In fact, passion is key to how Angela Duckworth speaks about the beneficial outcomes of grit. In a recent interview, she noted, "I think the misunderstanding - or, at least, one of them-is that it's only the perseverance part that matters [...] But I think that the passion piece is at least as important. I mean, if you are really, really tenacious and dogged about a goal that's not meaningful to you, and not interesting to you-then that's just drudgery. It's not just determination-it's having a direction that you care about" (as cited in ref. 12).

The present research brings passion back into the conceptualization and measurement of grit. We propose that only the combination of the current grit measure, the Grit-S scale (6) which emphasizes perseverance-with a measure that assesses whether individuals attain desired levels of passion will predict higher performance. Furthermore, we hypothesize that immersion will be a key route through which the combination of perseverance and passion attainment will improve performance. We test these propositions in a metaanalysis, a field study with employees at a technology company, and a field study of undergraduate students.

\section{The Absence of Passion in Grit Literature and Measurement}

From its inception, grit has theoretically stood on the dual pillars of perseverance and passion. The definition of grit includes the word passion: "perseverance and passion for long-term goals" (5). Drawing on, integrating, and extending prior conceptualizations of passion (21-24), ${ }^{*}$ we define passion as a strong feeling toward a personally important value/preference that motivates intentions and behaviors to express that value/preference. We use the words "a strong feeling" to indicate that passion is an intense affective state, but one that is not necessarily limited to positive emotions alone $(21,24)$. We use the phrase "toward a personally important value/preference" to denote that the target of passion reflects an attribute that has high personal value or strong appeal to the individual $(21,23)$. This builds on prior notions that passion is domain-specific, such as passion for hobbies, relationships, or work $(23,25,26)$. We use the phrase "that motivates intentions and behaviors to express that value/ preference" to capture that passion leads individuals to consistently desire engaging and interacting with this personally important value/preference: that is, the target of their passion $(22,24)$.

Despite the conceptual importance of passion in grit, there are theoretical and empirical concerns about whether the grit scale truly captures passion. The scale used to assess grit features two components-cpersistence of effort" and "consistency of interests" - the latter of which has been suggested to measure passion $(5,6)$. Theoretically, the claim that "consistency of interests" equates to passion is not supported by research. Although consistency of interests may be statistically correlated with personally important values/preferences, they are conceptually distinct. Consider this example: an academic may maintain a high

*Perttula KM, Annual Meeting of the Academy of Management, August 1-6, 2003, Seattle. consistency in an interest (e.g., the revision of manuscripts as part of the publication process), but the interest itself may have little personal importance (e.g., revising a manuscript on an unimportant topic).

Empirical results similarly cast doubt on the equivalence of consistency of interests and passion. Consider that a recent study finds no significant relationship between self-rated consistency of interests and other-rated passion (27). This concern is also borne out in a recent metaanalysis (8), which reports a corrected correlation of $\rho=0.60$ between "persistence of effort" and "consistency of interests." This correlation size supports the presence of a single construct (28), leading the authors of the metaanalysis (8) to conclude that the grit scale only measures the single factor of perseverance. This discrepancy may have occurred because the grit literature has not connected with prior passion research. In Duckworth et al.'s (5) paper introducing grit, the word "passion" only appears in the manuscript title, the definition of grit, and as a reference to a scale the authors discarded. In subsequent publications, there is no reference to passion other than including the word passion in the definition (4, 6, 29-31).

Taking these data together, we find that there is considerable theoretical and empirical evidence that the scale intended to measure both components of grit-perseverance and passionlikely captures only perseverance. We therefore subsequently refer to what the grit scale measures as perseverance. [The grit scale, developed by Duckworth et al. (5) contained 12 items, but was superseded by a shortened eight-item version of the grit scale (termed the Grit-S scale), which has superior psychometric qualities (6). In the studies described below, we focus on the Grit-S scale, which has been used predominantly since its publication.] We highlight why passion is a key component of grit's beneficial effects and propose that uncovering grit's predictive power requires adequate measurement of both perseverance and passion.

\section{Passion Attainment as a Key Component of Grit}

We propose that passion is a key ingredient of grit and needs to be empirically captured for a positive relationship between perseverance and performance to emerge. We suggest that passion is essential for perseverance to unfold its beneficial effects because it combines with perseverance to increase immersion in an activity, evidenced by increased focus and pursuit of activities related to their passionate endeavor (17-19). That is, the increased immersion produced by the combination of perseverance and passion leads individuals to devote greater cognitive effort and investment to their goals, as evidenced in more intense concentration (32). This heightened immersion, in turn, provides the energy and dedication that makes it more likely that individuals attain their goals $(33,34)$. Although perseverance helps individuals by remaining committed to their goal pursuit $(5,31)$, passion provides individuals with the focus necessary to achieve their goals $(4,29,35)$. Thus, when individuals pursue goals they are not passionate for, perseverance may not produce increased performance. In contrast, when employees pursue goals they are passionate for, higher perseverance may improve their performance.

Anecdotal evidence indicates that many highly persevering individuals achieve success only when pursuing goals they are passionate about. Consider the Italian singer Andrea Bocelli, who originally started his career as a lawyer, a course of study that requires substantial persistence, particularly given his blindness. Even while pursuing this field of study, Bocelli continued to sing at piano bars, but it was only when Bocelli allowed himself to be immersed in the pursuit of singing, "a passion he couldn't shake" (36), that he found success. This example illustrates that the purported benefits of the combination of perseverance and passion originally proposed by grit researchers requires the adequate measurement of both components of grit. 
In further understanding the role of passion, the current research highlights the importance of passion attainment: that is, whether people experience desired levels of passion (37). In prior research, passion has commonly been assessed using an adaptation of Vallerand et al.'s (23) harmonious passion scale, which was originally developed to assess how individuals feel about activities that are "very dear to their heart" (23). However, individuals commonly assess whether they are experiencing desired levels of passion $(38,39)$ and are guided by whether they have met this expectation (40-42). Indeed, a recent stream of research highlights that the experience of passion is guided by whether an individual attains or falls short of desired levels of passion and not by their absolute levels of harmonious passion (37). Thus, we propose that the combination of perseverance and passion attainment will predict performance.

\section{Study 1: Assessing the Role of Passion in Prior Studies}

To begin investigating the impact of the combination of perseverance and passion in predicting performance, we first reviewed prior studies in which the grit scale was used, and performance measured. A literature search yielded 127 studies $(n=45,485)$ (for more details on search and analyses, see Materials and Methods; see SI Appendix, Table S1 for list of studies included). Replicating prior research (8), we find a small but statistically significant effect of perseverance, as measured by the grit scale, on performance (estimate $=0.13, \mathrm{SE}=0.02, P<0.001)$ (see also SI Appendix, Fig. S1).

We hypothesized that in studies where participants were more likely to experience passion for a particular performance domain, the relationship between perseverance and performance would be stronger. To assess passion in prior research, three independent coders blind to the hypothesis of this study assessed whether the majority of participants in the study would find the performance domain personally important [interrater reliability $(I R R)=0.81]$, in line with prior theory and the definition of passion described above. For example, in a study of entrepreneurs starting their own companies (43), the majority of participants may consider the performance domain to be personally important. In contrast, college students taking a mandatory science class may consider the performance domain to be less personally important (44).

Our analysis suggests that passion levels of a performance domain moderate the relationship between perseverance and performance. That is, we found that in studies where participants likely experienced greater passion for a performance domain, there was a stronger relationship between perseverance and performance (moderator analysis of the metaanalytic effect: estimate $=0.07, \mathrm{SE}=0.04, P<0.05$ ) (see also SI Appendix, Fig. S2 and Table $\mathrm{S} 2$ for further information). This analysis thus provides preliminary support for our theory that passion moderates the relationship between perseverance and performance.

\section{Study 2: Performance Is Predicted by the Combination of Perseverance and Passion Attainment}

We next conducted a field study with employees at a technology company. We predicted that perseverance, as measured by the Grit-S scale, would only relate to increased supervisor-rated performance when employees attained desired levels of passion. In contrast, we predicted that for employees who did not attain desired levels of passion, there would be no significant relationship between perseverance and performance.

We tested this hypothesis with data from a technology company $(n=422)$, where we asked employees to respond to survey measures of perseverance (as measured by the eight-item Grit-S scale) and passion attainment (with a previously developed and validated three-item scale) (see also refs. 37 and 45). We then matched employees' survey responses to supervisor-rated performance ratings. We subsequently ran additional analyses including various control variables (e.g., age, gender, tenure, motivation, and harmonious passion) (see SI Appendix for further information and SI Appendix, Table S3 for bivariate correlations).

Before testing our hypothesis, we assessed the distinctiveness of the constructs by conducting confirmatory factor (confirmatory fit index, CFI) analyses. We first loaded items of each construct onto their respective factor, and find that the fitindices were acceptable (46) (with the exception of the CFI): $\chi^{2}$ $(334)=845.64$, root mean square error of approximation $($ RMSEA $)=0.06$, CFI $=0.92$, standardized root mean square residual $(\mathrm{SRMR})=0.08$. We then compared this model to a model where we loaded all items from every measure on one common factor. This model fit the data worse: $\chi^{2}(350)=$ 3110.19 , RMSEA $=0.14, \mathrm{CFI}=0.55, \mathrm{SRMR}=0.12$. Additionally, the fit of the first model was significantly better: $\Delta \chi^{2}=$ $2264.55, \Delta \mathrm{df}=16, P<0.001$. In addition, analyses reveal that the full Grit-S scale represents a single factor, which we label perseverance, and that this scale is distinct from the passion attainment measure (see SI Appendix for these and additional confirmatory factor analyses).

Our hypothesis was that the interaction between perseverance and passion attainment predicts job performance (SI Appendix, Table S4). Because supervisors assessed multiple employees, the data structure is nested; we therefore centered the variables and applied multilevel analyses (47) (SI Appendix). As shown in model 2 , the interaction effect was both positive and statistically significant (estimate $=0.03, \mathrm{SE}=0.01, \gamma=0.14, P=0.02$ ) and accounted for an additional $2 \%$ of variance in job performance. The highest job performance occurred when both perseverance and passion attainment were high, as depicted in Fig. 1. This finding was empirically supported through simple slopes analyses (SI Appendix).

We subsequently tested whether our results remain statistically significant when adding the control variables. As SI Appendix, Table S4 shows, the interaction effect remains statistically significant in all models (model 3 adding in gender, age, and organizational tenure: estimate $=0.03, \mathrm{SE}=0.01, \gamma=0.16, P=$ 0.01 ; model 4 adding in harmonious passion, prosocial, intrinsic, and extrinsic motivation: estimate $=0.03, \mathrm{SE}=0.01, \gamma=0.16$, $P=0.01$; model 5 adding in the interaction between perseverance and harmonious passion: estimate $=0.04, \mathrm{SE}=0.01, \gamma=$ $0.19, P<0.001)$. The values of the simple slopes also remained the same. These results provide support for our hypothesis that the combination of perseverance and passion attainment predict performance.

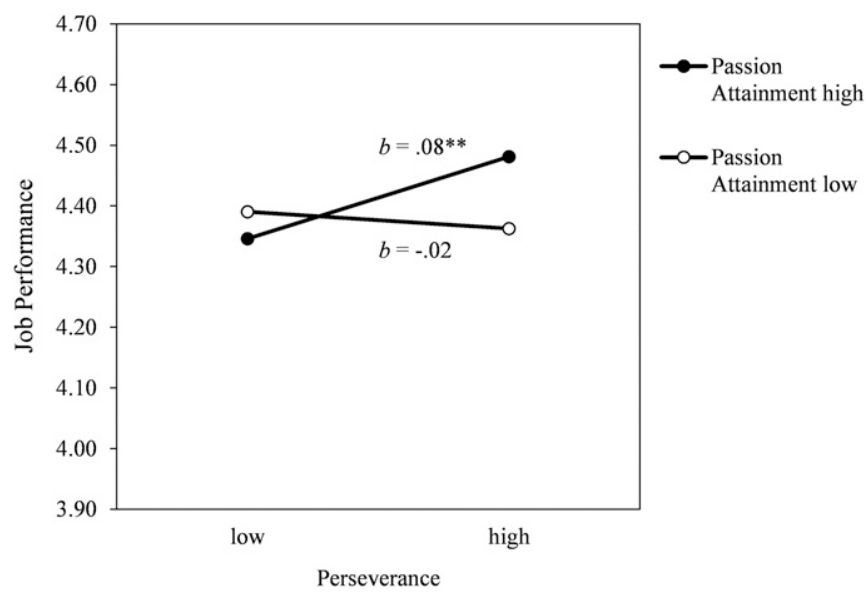

Fig. 1. Study 2: Passion attainment moderates the relationship between perseverance and performance. 


\section{Study 3: Immersion as One Mediator of the Relationship Between Perseverance and Passion on Performance}

Our final study explored one mechanism through which the combination of perseverance and passion attainment would predict performance: by promoting immersion. We recruited 248 currently enrolled students at a private university in the United States and asked them to fill out the same measures of perseverance and passion attainment as in the prior study. We also asked students to upload their current grade transcript and used their major grade point average (GPA) as a measure of their performance (see SI Appendix for further information). In addition, we measured our hypothesized mediator-immersionusing three items adapted from the Utrecht Work Engagement Scale (20). The items were, "When I am working on activities related to my courses, I forget everything else around me," "I get immersed in activities related to my courses," and "I get carried away working on activities related to my courses" (see SI Appendix, Table S5 for bivariate correlations).

This study replicated our earlier results (see SI Appendix for confirmatory factor analyses and additional analyses). SI $\mathrm{Ap}$ pendix, Table S6 shows the analyses regressing the interaction of perseverance and passion attainment on performance. As shown in model 2 , the corresponding interaction effect was both positive and statistically significant (estimate $=0.18, \mathrm{SE}=0.06, P=$ 0.001 ), such that perseverance was related to higher performance at higher levels of passion attainment $(+1 \mathrm{SD}$; estimate $=0.36$, $\mathrm{SE}=0.08, P<0.001)$ but not at lower levels of passion attainment $(-1 \mathrm{SD}$; estimate $=-0.01, \mathrm{SE}=0.09, P=0.91)$.

We next tested for the mediation through immersion. To do so, we first regressed the interaction of perseverance and passion attainment on immersion and find a statistically significant interaction effect (estimate $=0.19, \mathrm{SE}=0.05, P<0.001$ ); perseverance was related to higher immersion only at higher levels of passion attainment $(+1 \mathrm{SD}$; estimate $=0.31, \mathrm{SE}=0.08, P<$ $0.001)$ but not at lower levels of passion attainment $(-1 \mathrm{SD}$; estimate $=-0.08, \mathrm{SE}=0.08, P=0.33$ ). Given the positive correlation between immersion and performance $(r=0.36, P<$ 0.001 ), we next tested for mediated moderation, with perseverance and passion attainment as the independent variables, immersion as the mediator, and performance as the dependent variable, using bias-corrected bootstrapping with 10,000 resamples to construct $95 \%$ confidence intervals (CI) for the conditional indirect effects (48). We found that the $95 \% \mathrm{CI}$ of the mediated moderation excludes zero $(0.002 ; 0.086)$, demonstrating a statistically significant indirect effect. Subsequent analyses revealed that the indirect path from perseverance to performance via immersion was statistically significant only when passion attainment was higher [+1 SD; 95\% CI $(0.029 ; 0.173)]$ but not when passion attainment was lower $[-1 \mathrm{SD} ; 95 \% \mathrm{CI}$ $(-0.084 ; 0.025)]$. These results indicate that passion attainment significantly moderates the indirect effect of perseverance on performance through immersion, such that at higher levels of passion attainment, the positive relationship between perseverance and immersion is statistically significant, resulting in higher performance. Given that the interaction of perseverance and passion attainment on performance remained statistically significant when including immersion (from estimate $=0.18, \mathrm{SE}=0.06$, $P=0.001$ to estimate $=0.13, \mathrm{SE}=0.05, P=0.016)$, the relationship between the interaction of perseverance and passion attainment on performance travels in part through immersion.

\section{Discussion}

The relationship between grit and performance has created a firestorm of contradictory results. The current research proposed that this inconsistency has occurred because even though the definition of grit includes perseverance and passion, the grit measure solely reflects perseverance and does not adequately capture passion. Instead, we suggest that a combination of the Grit-S scale-which we propose captures perseverance alonewith a measure that assesses passion attainment would predict performance. Across a metaanalysis and two field studies, we provide support for this prediction: only the combination of perseverance and passion attainment predicted performance. In addition, we find that this relationship occurs in part through increased immersion. By adequately measuring both perseverance and passion attainment, the current research uncovers grit's predictive power.

The explicit connection to the passion literature is important because grit researchers have conceptually proposed that passion is essential for perseverance to have a positive effect on performance (5). The interactive effect of perseverance and passion attainment provides evidence that perseverance only propels employees forward when they experience desired levels of passion (24). We further advance prior literature by uncovering one underlying mechanism: the combination of high perseverance and high passion attainment increases performance by promoting the intensity of focus individuals' experience $(17,19,20)$. Finally, the present studies also address prior calls to examine the effects of grit outside of scholastic performance (8).

The present research has limitations that provide opportunities for future research. The study designs were cross-sectional, which omits the possibility of investigating potential long-term effects of grit. In addition, the cross-sectional nature of our studies does not allow us to address concerns about reverse causality: it is possible that individuals who performed worse also reported lower passion attainment, changing their attitudes as a response to negative feedback regarding their competence (49). This concern was addressed in study 2 , where supervisor-rated performance ratings - although collected immediately before the survey-were only disclosed to employees after the survey data collection was completed. Nonetheless, future research should further investigate the causal nature of the interactive effect of perseverance and passion attainment. Furthermore, the crosssectional nature of studies 2 and 3 does not exclude the occurrence of common method variance for the independent variables. However, given that we studied the moderating effect of passion attainment on the relationship between perseverance and performance, the presence of common method variance should have made it more difficult to find such effects (50-53). Finally, future research may consider adapting the grit scale to a particular performance domain to increase its predictive capacity in that domain (e.g., work). The present grit scale currently assesses perseverance more generally (6), but subsequent investigations could explore the value of assessing more specific perseverance.

Our findings suggest that perseverance without passion attainment is mere drudgery, but perseverance with passion attainment propels individuals forward. By incorporating passion into the conceptualization and measurement of grit, future research may find that grit actually lives up to its hype.

All studies were approved by the Columbia University Institutional Review Board and all participants provided informed consent.

\section{Materials and Methods}

Study 1. We conducted a metaanalysis of studies that used both the grit scale and assessed performance. We hypothesized that in contexts where participants would find the performance domain to be personally relevant, they would experience greater passion. In these settings, we expected to find a moderating effect on the relationship between perseverance and performance, such that the relationship between perseverance and performance is stronger when participants' passion for the performance domain is higher. Literature search. We began our search strategy began by reviewing all of the studies included in the most recent meta-analysis of grit (8). We then reviewed all subsequent citations of said metaanalysis using PsychINFO, Web of Science, and Google Scholar online databases using the search term 
"grit." Additionally, we sent out a call for unpublished data to two academic listservs, the Society for Personality and Social Psychology, and the Association for Research in Personality. This search yielded a total of 253 datasets. We then reviewed each paper based on the inclusion criteria to develop our final sample (see below). The search was completed in May of 2018. The metaanalysis data and code are available via the Open Science Framework (https://osf.io/kp7cb/)

Criteria for inclusion and exclusion. Our primary metric of interest was the Pearson correlation coefficient between the grit scale and a measure of performance relevant to that study's sample. If the Pearson correlation coefficient was not reported directly but was available through other sources, the study was included in our final sample. In cases where the Pearson's $r$ coefficient was not reported, a $t$-statistic, or a $\beta$-coefficient for a regression of grit on performance was recorded and converted into $r$. If the correlation was not reported directly and was not available through other sources, we contacted the first author of the paper with a request for the correlation coefficient. Studies were not excluded based on the location of the sample nor were any studies excluded based on publication information. We did not exclude papers based on the age of the participants, although subsequent analyses were done to examine variation by age and the differences did not qualify our findings in a meaningful way. Studies were excluded when they did not contain measures of performance, meaning that studies that only measured characteristics such as retention, well-being, or satisfaction were excluded. We also excluded studies that focused on negative behaviora characteristics (e.g., suicide, gambling). Additionally, three papers were excluded because they used duplicate datasets to studies included in the final sample. After thorough review of the papers based on the above qualifications, our final sample was determined with 127 studies, and a total of 45,485 participants ( $n$ s ranging from 21 to 4,800). All analyses were conducted in $R$ using the statistical packages metafor (v2.0), and MAc (v1.1). Coding procedure. All papers were coded by two authors (J.M.J. and E.R.B.) and all disagreements were resolved through internal discussion. The following data were collected from each study: Pearson's $r$ correlation between the grit scale and performance, the type of performance metric, sample size, if the article was published in a peer-reviewed journal, the year of the study, and the journal type (psychology, education, other). In addition, three independent coders were instructed to code a binary variable indicating whether or not the majority of participants in the study would deem the performance domain to be personally important. The coders were blind to the hypothesis of this paper and had a high degree of interrater reliability (IRR $=0.81)$. Disagreements were discussed and resolved in subsequent coding review sessions.

\section{Study 2.}

Participants and procedure. The study was conducted with employees of a technology company located in a Spanish-speaking country. Employees work in teams guided by a supervisor who also provides annual evaluations of subordinates with an organizationally developed measure of job performance. Employees were contacted by an email sent out by J.M.J, which contained a link to the survey hosted on https://Qualtrics.com. Employees were guaranteed that their responses would be kept entirely confidential, and that their employer would not have access to any of their responses. The email was sent out to all of the firm's 2,293 employees, and 178 emails bounced back. In addition to the employee survey data, the company's Human Resources team provided performance ratings for each employee, which were conducted in the month before the survey was sent to employees.

Before our data collection, we conducted an a priori power analysis using conventional values for a small to medium effect size $\left(f^{2}=0.075, \alpha=0.05, \beta=\right.$ 0.95; three variables) (45), as would be expected for typical interaction effects in social science (ranging from 3 to $10 \%)(46,47)$. Calculations reveal that we would need a sample of 176 participants to be able to detect an effect of our hypothesized two-way interaction.

We received partial survey data from 1,265 employees and could match 560 employee-supervisor dyads. After dropping dyads with missing data on our focal variables, or where we were unable to identify the corresponding supervisors, our final sample consisted of 422 employees (response rate: $33.5 \%$ ). This subset of employees did not differ in age, gender, or tenure from partial respondents (all $P S>0.22$ ). Our sample included 169 female employees, ages ranged from 18 to $63 \mathrm{y}$ (mean $=30.96 \mathrm{y}, \mathrm{SD}=6.99$ ), and employees had been working in the organization for an average of $3.69 \mathrm{y}$ $(S D=2.88)$. Overall, 85 supervisors provided performance ratings with an average of five subordinate ratings per supervisor $(S D=5.25)$.

Measures. Given the company's location, we used the translation procedure outlined by Schaffer and Riordan (54) to adapt our measures to Spanish.
Where not stated otherwise, the measures used a seven-point scale ranging from "strongly disagree" to "strongly agree."

Perseverance. To measure perseverance, we used the Short Grit Scale (GritS) (6), which has improved psychometric properties over the full Grit Scale (6), and consists of four items each for two different factors, "perseverance of effort" and "consistency of interests." Sample items are "I have overcome setbacks to conquer an important challenge (perseverance of effort)" and " often set a goal but later choose to pursue a different one (reversed; consistency of interest)." Following prior research $(5,6)$, we computed an average score across both subcomponents, $\alpha=0.73$.

Passion attainment. We measured the extent to which employees feel they attained their desired level of passion for their work with three previously developed and used items $(37,45)$. These items read "I am less passionate for my work than I should be," "I often feel as if I have to be more passionate for my work," and "I frequently feel obliged to be more pas sionate for my work than I currently am." We reverse-scored the items, such that higher levels corresponded to increased passion attainment, $\alpha=0.82$.

Harmonious passion. To highlight that the results are driven by passion attainment, we also assessed harmonious passion with Vallerand et al.'s (23) harmonious passion scale $(\alpha=0.90)$. Sample items include "My work is in harmony with the other activities in my life" and "My work is well integrated in my life."

Job performance. We used the organization-wide measure to assess performance which supervisors use for annual performance evaluation. This measure was conducted and provided by the Human Resources department of the company and covers different aspects of work that are important for the organization. The performance measure varies on a scale of 1 (very poor performance) to 5 (very good performance). Given the average job performance score of 4.39 ( $S D=0.52)$, we further evaluated the skewness and kurtosis of the performance measure. Both skewness $(-0.80)$ and kurtosis (0.23) were acceptable (55).

Control variables. In our analyses, we also controlled for age, gender, tenure, and motivation. Age was included because older people tend to receive worse performance evaluations (56) and perseverance increases with age (6). We controlled for gender because research cannot rule out whether female employees receive worse performance ratings (57), and for organizational tenure because it has been shown to be related to job performance (58). Finally, to distinguish our effects of the interaction between perseverance and passion attainment from motivation (31), and to provide a more rigorous test of our hypothesis, we also controlled for prosocial $(\alpha=0.85$ ), intrinsic $(\alpha=0.88)$, and extrinsic $(\alpha=0.83)$ motivation using measures from Grant (59). We included all control variables in subsequent steps after first testing our predicted interaction effect separately following recommendations by Becker (60) and Becker et al. (61) to avoid spurious results in our hypothesis tests.

Study 3.

Participants and procedure. The study was conducted with students at a private northeastern university. Participants were contacted by an email sent out by the university laboratory's recruitment mailing list, which contained a link to the survey hosted on https://Qualtrics.com. Participants were guaranteed that their responses would be kept entirely confidential.

Before our data collection, we conducted an a priori power analysis using conventional values for a small to medium effect size $\left(f^{2}=0.075, \alpha=0.05, \beta=\right.$ 0.95; three variables) (45), as would be expected for typical interaction effects in social science (ranging from 3 to $10 \%)(46,47)$. Calculations reveal that we would need a sample of 176 participants to be able to detect an effect of our hypothesized two-way interaction. We succeeded in obtaining responses from 248 participants (mean age: $21.66 \mathrm{y}, 70.56 \%$ female).

Measures. Where not stated otherwise, the measures used a seven-point scale ranging from "strongly disagree" to "strongly agree."

Perseverance. We measured perseverance using the same eight-item measure as above ( $\alpha=0.73$ ).

Passion attainment. We measured passion attainment using the same threeitem measure as above. Same as before, we reverse-scored the items, such that higher levels corresponded to increased passion attainment, $\alpha=0.88$.

Performance. Participants were asked to report their major GPA. For verification purposes, we also asked students to upload their grade transcript to the online survey. Past literature has often relied on GPA as a measure of performance, because of its consistency across a large sample and its impact on graduation, honors, and job-seeking (see, for example, refs. 5 and 30). Major GPAs ranged from 2.1 (equivalent to a $C$ average) to 4.33 (equivalent to an $A+$ average). Given the average major GPA of $3.52(S D=0.47)$, we 
further evaluated both the skewness $(-0.94)$ and kurtosis $(0.29)$, which were acceptable (55).

Control variables. Finally, we measured participants' age and gender, their year of study, and major.

1. Duckworth AL (2013) Grit: The power and passion of perseverance [video recording] Available at https://www.ted.com/talks/angela lee_duckworth_grit_the_power_of passion_and_perseverance. Accessed August 30, 2018.

2. Duckworth AL (2016) Grit: The Power of Passion and Perseverance (Scribner, New York).

3. Smith T (2014) Does teaching kids to get "gritty" help them get ahead? NPR. Available at https://www.npr.org/sections/ed/2014/03/17/290089998/does-teaching-kids-toget-gritty-help-them-get-ahead. Accessed August 30, 2018.

4. Duckworth AL, Kirby TA, Tsukayama E, Berstein H, Ericsson KA (2011) Deliberate practice spells success: Why grittier competitors triumph at the National Spelling Bee. Soc Psychol Personal Sci 2:174-181.

5. Duckworth AL, Peterson C, Matthews MD, Kelly DR (2007) Grit: Perseverance and passion for long-term goals. J Pers Soc Psychol 92:1087-1101.

6. Duckworth AL, Quinn PD (2009) Development and validation of the short grit scale (grit-s). J Pers Assess 91:166-174.

7. Lucas GM, Gratch J, Cheng L, Marsella S (2015) When the going gets tough: Grit predicts costly perseverance. J Res Pers 59:15-22.

8. Credé M, Tynan MC, Harms PD (2017) Much ado about grit: A meta-analytic synthesis of the grit literature. J Pers Soc Psychol 113:492-511.

9. Ivcevic Z, Brackett M (2014) Predicting school success: Comparing conscientiousness, grit, and emotion regulation ability. J Res Pers 52:29-36.

10. Rimfeld K, Kovas Y, Dale PS, Plomin R (2016) True grit and genetics: Predicting academic achievement from personality. J Pers Soc Psychol 111:780-789.

11. Useem J (2016) Is grit overrated? Atlantic. Available at https://www.theatlantic.com/ magazine/archive/2016/05/is-grit-overrated/476397/. Accessed August 30, 2018.

12. Dahl M (2016) Don't believe the hype about grit, pleads the scientist behind the concept. New York Magazine. Available at https://www.thecut.com/2016/05/dont believe-the-hype-about-grit-pleads-the-scientist-behind-the-concept.html. Accessed August 30, 2018

13. Barshay J (2016) Grit under attack in education circles. US News. Available at https:// www.usnews.com/news/articles/2016-04-18/grit-under-attack-in-education-circles.

14. Denby D (2016) The limits of "grit." The New Yorker. Available at https://www. newyorker.com/culture/culture-desk/the-limits-of-grit. Accessed August 30, 2018.

15. Strauss V (2015) Why teaching kids to have "grit" isn't always a good thing The Washington Post. Available at https://www.washingtonpost.com/news/answersheet/wp/2015/05/14/why-teaching-kids-to-have-grit-isnt-always-a-good-thing/?noredirect $=$ on. Accessed August 30, 2018

16. Kamenetz A (2016) MacArthur "genius" Angela Duckworth responds to a new critique of grit. NPR. Available at https://www.npr.org/sections/ed/2016/05/25/479172868/angeladuckworth-responds-to-a-new-critique-of-grit. Accessed August 30, 2018.

17. Dumas TL, Smith JEP (2018) The paradox of family structure and plans after work: Why single childless employees may be the least absorbed at work. Acad Manage 61:1231-1252.

18. Mitteness CR, Cardon MS, Sudek R (2010) The importance angels place on passion when making investment decisions: Why does it matter to some and not all angels? Front Entrep Res 30:2

19. Ho VT, Wong SS, Lee CH (2011) A tale of passion: Linking job passion and cognitive engagement to employee work performance. J Manage Stud 48:26-47.

20. Schaufeli WB, Bakker AB, Salanova M (2006) The measurement of work engagement with a short questionnaire: A cross-national study. Educ Psychol Meas 66:701-716.

21. Chen XP, Yao X, Kotha S (2009) Entrepreneur passion and preparedness in business plan presentations: A persuasion analysis of venture capitalists' funding decisions. Acad Manage J 52:199-214.

22. Cardon MS, Wincent J, Singh J, Drnovsek M (2009) The nature and experience of entrepreneurial passion. Acad Manage Rev 34:511-532.

23. Vallerand RJ, et al. (2003) Les passions de l'ame: On obsessive and harmonious pas sion. J Pers Soc Psychol 85:756-767.

24. Perrewé PL, Hochwarter WA, Ferris GR, McAllister CP, Harris JN (2014) Developing a passion for work passion: Future directions on an emerging construct. $J$ Organ Behav 35:145-150.

25. Bonneville-Roussy A, Lavigne GL, Vallerand RJ (2011) When passion leads to excellence: The case of musicians. Psychol Music 39:123-138.

26. Mageau GA, et al. (2009) On the development of harmonious and obsessive passion The role of autonomy support, activity specialization, and identification with the activity. J Pers 77:601-646.

27. Grohman MG, Ivcevic Z, Silvia P, Kaufman SB (2017) The role of passion and persistence in creativity. Psychol Aesthetics Creativity Arts 11:376-385.

28. Judge TA, Erez A, Bono JE, Thoresen CJ (2002) Are measures of self-esteem, neuroticism, locus of control, and generalized self-efficacy indicators of a common core construct? J Pers Soc Psychol 83:693-710.

29. Eskreis-Winkler L, Shulman EP, Beal SA, Duckworth AL (2014) The grit effect: Predicting retention in the military, the workplace, school and marriage. Front Psychol $5: 36$

30. Robertson-Kraft C, Duckworth AL (2014) True grit: Trait-level perseverance and passion for long-term goals predicts effectiveness and retention among novice teachers. Teach Coll Rec 116:1-27.
ACKNOWLEDGMENTS. We thank Angela Duckworth, Kristen Duke, Lauren Eskreis-Winkler, Andrea Freund, Sandra Matz, Evan Nesterak, Christopher To, Aurora Turek, and Kristina Wald for critical feedback, which substantially improved this paper.

31. Von Culin KR, Tsukayama E, Duckworth AL (2014) Unpacking grit: Motivational correlates of perseverance and passion for long-term goals. J Posit Psychol 9:306-312.

32. Rothbard NP (2001) Enriching or depleting? The dynamics of engagement in work and family roles. Adm Sci $Q$ 46:655-684.

33. Sonnentag S (2003) Recovery, work engagement, and proactive behavior: A new look at the interface between nonwork and work. J Appl Psychol 88:518-528.

34. Salanova M, Bakker AB, Llorens S (2006) Flow at work: Evidence for an upward spiral of personal and organizational resources. J Happiness Stud 7:1-22.

35. Locke EA (1968) Toward a theory of task motivation and incentives. Organ Behav Hum Perform 3:157-189.

36. Smiley T (2015) Interview with Andrea Bocelli [television interview]. PBS. Aired December 8, 2015.

37. Jachimowicz JM, To C, Menges Jl, Akinola M (2018) Igniting passion from within: How lay beliefs guide the pursuit of work passion and influence turnover intentions. PsyArxiv, 10.31234/osf.io/qj6y9. Preprint, posted June 28, 2018. Available at https:// psyarxiv.com/qj6y9. Accessed August 30, 2018.

38. Major D, Kozlowski SWJ, Chao GT, Gardner PD (1995) A longitudinal investigation of newcomer expectations, early socialization outcomes, and the moderating effects of role development factors. J Appl Psychol 80:418-431.

39. Buckley MR, Fedor DB, Veres JG, Wiese DS, Carraher SM (1998) Investigating newcomer expectations and job-related outcomes. J App/ Psychol 83:452-461.

40. Wilson TD, Lisle DJ, Kraft D, Wetzel CG (1989) Preferences as expectation-driven inferences: Effects of affective expectations on affective experience. $J$ Pers Soc Psychol 56:519-530.

41. Podsakoff NP, LePine JA, LePine MA (2007) Differential challenge stressor-hindrance stressor relationships with job attitudes, turnover intentions, turnover, and withdrawal behavior: A meta-analysis. J Appl Psychol 92:438-454.

42. Wanous JP, Poland TD, Premack SL, Davis KS (1992) The effects of met expectations on newcomer attitudes and behaviors: A review and meta-analysis. J Appl Psychol 77: 288-297.

43. Mueller BA, Wolfe MT, Syed I (2017) Passion and grit: An exploration of the pathways leading to venture success. J Bus Venturing 32:260-279.

44. Bazelais P, Lemay DJ, Doleck T (2016) How does grit impact college students' academic achievement in science? Eur J Sci Math Educ 4:33-43.

45. Jachimowicz JM, Wihler A, Galinsky AD (2018) When the passionate succeed: Employees' passion attainment predicts job performance only when their supervisors' passion attainment is higher. PsyArxiv, 10.31234/osf.io/u8g3h. Preprint, posted June 19, 2018. Available at https://psyarxiv.com/u8g3h/. Accessed August 30, 2018.

46. Schermelleh-Engel K, Moosbrugger $H$, Müller $H$ (2003) Evaluating the fit of structural equation models: Tests of significance and descriptive goodness-of-fit measures. Methods Psychol Res 8:23-74.

47. Hox JJ (2010) Multilevel Analysis: Techniques and Applications (Routledge, New York)

48. Hayes AF (2013) Introduction to Mediation, Moderation, and Conditional Process Analysis: A Regression-Based Approach (Guilford Press, New York).

49. Wicklund RA, Brehm JW (1968) Attitude change as a function of felt competence and threat to attitudinal freedom. J Exp Soc Psychol 4:64-75.

50. Siemsen E, Roth AV, Oliveira P (2010) Common method bias in regression models with linear, quadratic, and interaction effects. Organ Res Methods 13:456-476.

51. Cohen J (1988) Statistical Power Analysis for the Behavioral Sciences (Lawrence Erlbaum Associates, Hillsdale, NJ).

52. Chaplin WF (1991) The next generation of moderator research in personality psychology. J Pers 59:143-178.

53. Champoux JE, Peters WS (1987) Form, effect size and power in moderated regression analysis. J Occup Psychol 60:243-255.

54. Schaffer BS, Riordan CM (2003) A review of cross-cultural methodologies for organizational research: A best-practices approach. Organ Res Methods 6:169-215.

55. Curran PJ, West SG, Finch JF (1996) The robustness of test statistics to nonnormality and specification error in confirmatory factor analysis. Psychol Methods 1:16-29.

56. Waldman DA, Avolio BJ (1986) A meta-analysis of age differences in job performance. J Appl Psychol 71:33-38.

57. Bowen C-C, Swim J, Jacobs RR (2000) Evaluating gender biases on actual job performance of real people: A meta-analysis. J App/ Soc Psychol 30:2194-2215.

58. Ng TWH, Feldman DC (2010) Organizational tenure and job performance. J Manage 36:1220-1250.

59. Grant AM (2008) Does intrinsic motivation fuel the prosocial fire? Motivational synergy in predicting persistence, performance, and productivity. J App/ Psychol 93: 48-58.

60. Becker TE (2005) Potential problems in the statistical control of variables in organizational research: A qualitative analysis with recommendations. Organ Res Methods 8:274-289.

61. Becker TE, et al. (2016) Statistical control in correlational studies: 10 essential recommendations for organizational researchers. J Organ Behav 37:157-167. 